Such hospital-based navigators are most common for patients with breast cancer because the cost of hiring them can be absorbed through the millions of dollars raised through fundraising for breast cancer, Russell says. "The idea is catching on. But I certainly wouldn't say anyone with a breast cancer diagnosis would [automatically] be given a navigator."

Barriers to treatment led to the notion of appointing someone to help patients with breast cancer negotiate their way through the system, says the so-called "father" of patient navigation, Dr. Harold Freeman.

Freeman's studies of roughly 600 women with breast cancer seeking treatment at the Harlem Hospital in New York City during the 1970s indicated that roughly $39 \%$ were alive after five years and only $6 \%$ had been diagnosed with early, stage one breast cancer (www.ncbi .nlm.nih.gov/pubmed/2720605).

That led Freeman to help establish two sites at which women could get free breast cancer screenings. But he soon discovered that the sites were only half the solution, as women who were showing abnormalities in their screenings were not seeking follow-up treatment because of financial, cultural or communication barriers. "The thing I later began to call navigation was born out of that experience of how to get people from finding to resolution in a timely manner," he says.

In 1990, Freeman developed the first patient navigation program at Harlem
Hospital, basing it on a community program in which a peer met with a patient to determine whether any barriers existed to following prescribed treatments. Finances were invariably an issue, particularly for those who lacked health insurance, Freeman says.

A subsequent study surveyed 300 women with breast cancer and found that those who received free screening and navigation saw their five-year survival rate rise to $70 \%$ from $39 \%$.

The results formed the basis for the US Congress's decision to pass the Patient Navigator Outreach and Chronic Disease Prevention Act in 2005, which authorized the spending of US\$25 million over five years to set up navigation services in poor and rural communities. There are now about 20 such local programs.

Freeman also argues that navigators are cost-effective.

Not all navigators must be medical professionals, he says. "Ultimately, to be successful and supported by governments and hospitals, navigation needs to be cost-effective so it doesn't make sense to assign a highly trained professional to do a task that can be done by a lay person for example."

A nurse oncologist isn't needed to iron out financial issues, he adds. "There are navigation tasks and phases that can be done quite well by people who don't have professional training."

Still, there appears to be a desire to elevate the status of navigators to that of medical professionals and to that end, the Harold P. Freeman Patient Navigation Institute was created in 2007 to train people from around the world on the nuances of being a patient navigator.

The reality, though, is that navigators in the US are currently unregulated and as a consequence, patients should be wary, Russell says. "There's no single credential, no state-regulated licenser, which means it's important for people to know what they're getting into if they decide to hire someone." While some private firms are offering to certify navigators, that's no guarantee of competence, she adds. "You have to do your homework."

The onslaught of private certification programs has led Russell and other private navigators to form a national association of navigators in hopes of guiding the growth of the industry and ultimately elevating its level of professionalism. The National Association of Healthcare Advocacy Consultants already has roughly 240 members, has crafted a code of ethics, and is now developing a set of practice standards. — Erin Walkinshaw, Ottawa, Ont.

CMAJ 2011. DOI:10.1503/cmaj.109-3973

First of a two-part series.

Part II: Patient navigators becoming the norm in Canada (www.cmaj.ca /lookup/doi/10.1503/cmaj.109-3974).

\title{
Backlash against nonconventional therapy guidelines
}

$\mathrm{P}$ atient safety and professional ethics may be compromised by proposed Ontario guidelines on how doctors should acknowledge and incorporate alternative therapies in their practices, professional and regulatory bodies charge.

The groups argue that the College of Physicians and Surgeons of Ontario's (CPSO) draft guidelines, Non-Allopathic (Non-Conventional) Therapies in Medical Practice, apply a lower evidentiary bar for measuring the safety and efficacy of complementary medicine therapies and are effectively asking physicians to counsel patients to undertake unscientific health practices.

In panning the guidelines, the groups also argue that physicians will be placed in the position of breaching their duty to provide patients with the best possible care.

CPSO is currently fielding submissions in response to draft guidelines that would compel physicians "to propose both allopathic and non-allopathic ther- apeutic options that are clinically indicated or appropriate" (www.cpso.on.ca /uploadedFiles/policies/consultations/non -allopathic-consultation-draft.pdf).

All nonallopathic therapies that a physician proposes must:

- "have a demonstrable and reasonable connection, supported by sound clinical judgement, to the diagnosis reached;

- possess a favourable risk/benefit ratio, based on the merits of the option, the potential interactions 
with other treatments the patient is receiving, and other considerations the physician deems relevant;

- take into account the patient's socioeconomic status when the cost will be borne by the patient directly; and

- have a reasonable expectation of remedying or alleviating the patient's health condition or symptoms."

The type of evidence required for making the latter determination "will depend on the nature of the therapeutic option in question, including, the risks posed to patients, and the cost of the therapy," the guidelines add. "Those options that pose greater risks than a comparable allopathic treatment or that will impose a financial burden, based on the patient's socio-economic status, must be supported by evidence obtained through a randomized clinical trial that has been peer-reviewed."

When effectiveness or risk associated with a nonconventional therapy is unknown, physicians should "proceed in a cautious and ethical manner."

Physicians should also disdain from expressing opinions that nonconventional therapies are a form of quackery, the guidelines add. "Patients are entitled to make treatment decisions and to set health care goals that accord with their own wishes, values and beliefs. This includes decisions to pursue or to refuse allopathic or non-allopathic therapies. The College expects physicians to respect patients' treatment goals and decisions, even those which physicians deem to be unfounded or unwise. In doing so, physicians should state their best professional opinion about the goal or decision, but must refrain from expressing non-clinical judgements."

The guidelines are an acknowledgement that "the popularity of these therapies amongst patients has increased; the types of available therapies has increased; and a broad range of individuals are providing care, including physicians, other regulated professionals and some unregulated professionals," says CPSO Registrar Dr. Rocco Gerace.

The response to the guidelines, though, has been less than enthusiastic. That includes criticism from professional bodies such as the Canadian Medical Association, which argued in its submission that the guidelines suggest a false equivalence between conventional and alternative medical approaches.

"The use of complementary and alternative medicine in Canada should be founded on sound scientific evidence as to its safety, efficacy and effectiveness: the same standard by which physicians and all other elements of the health care system should be assessed. When alternative treatment modalities do demonstrate effectiveness, they are usually incorporated into the mainstream of

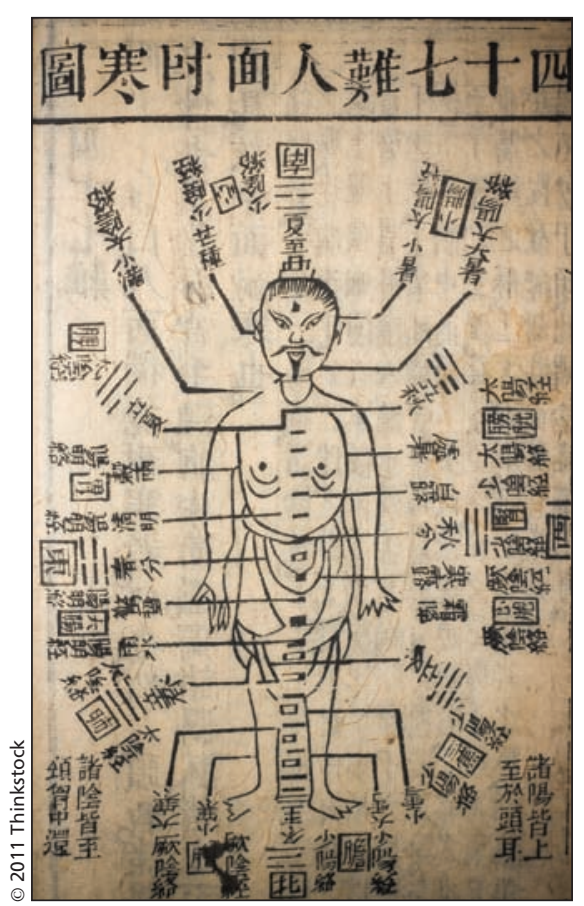

The College of Physicians and Surgeons of Ontario has proposed guidelines that would compel physicians "to propose both allopathic and non-allopathic therapeutic options that are clinically indicated or appropriate."

medicine. Therefore, one could argue that complementary and alternative therapies are by definition less demonstrably effective than conventional medical treatment" (www.cpso.on.ca/policies /consultations/default.aspx?id=5392).

The critics have also invariably trained their guns on the criteria that doctors are to use to determine whether a nonconventional therapy is effective and safe, and therefore falls under the umbrella of options for treatment that must be proposed to patients.

The guidelines suggest that the evidentiary standard is lower for therapies that are low-risk, even if they are likely to be less effective than a conventional, more rigorously tested therapy, argued the Committee for the Advancement of Scientific Skepticism, the "fast response team" of the Ottawa, Ontariobased educational charity, the Centre for Inquiry Canada, in its submission (www.cpso.on.ca/uploadedFiles/policies /consultations/CASS.pdf). "The standard for evidence required should be no lower for efficacy than it is for risk."

Several organizations have also argued that the language of the guidelines is altogether vague, particularly with regard to the provision that physicians should refrain from expressing a "non-clinical judgement" about a nonconventional therapy.

The guidelines may be "interpreted as impressing tight limits on physicians' ability to state their honest, scientifically sound objections to pseudo-scientific medical theories and ideas," the Committee for the Advancement of Scientific Skepticism contended. "Their non-conventional medical counterparts feel no such compunction in spreading misinformation about legitimate medical practices such as vaccination, as well as in misrepresenting the scientific standing of dubious non-conventional practices."

But Gerace counters that CPSO is not seeking to muzzle physicians. It's simply "a principle of good practice that physicians provide their professional opinion in an accurate and objective manner that is substantiated by fact and sound clinical judgement."

Opinion is never quite that simple and straightforward, others argued.

Although medical knowledge and opinion are not always "tied lock-step to the latest clinical trial results, they are informed by basic science principles and well-established pre-clinical information," stated the British Columbia Medical Association in its submission (www.cpso.on.ca/uploadedFiles/policies /consultations/110831-Feedback-BCMA .pdf). "Physicians can comment, therefore, in an informed way on the unlikely prospects for therapies like homeopathy or therapeutic touch that defy the very well-established laws of physics and chemistry but nonetheless enjoy the support of much less precise investigative tools such as poorly done clinical trials."

Moreover, "physicians cannot be expected to be knowledgeable about 
the myriad of unscientific health practices that currently exist," the association added. "Physicians should not be expected to have knowledge of alternative medicine any more than they would be expected to have knowledge in any other field of human endeavour outside of scientific medicine."

Others have raised concerns about a provision of the guidelines that suggests physicians should be more collegial and willing to refer patients to practitioners of nonconventional and alternative therapies.

Gerace says the intent is to encourage referrals in cases where it's in the best interest of patients and in the service of informed decision-making.
But the British Columbia Medical Association argued that the notion that physicians should collaborate with, or refer patients to, alternative practitioners “is not compatible with the doctor's duty to provide care that is consistent with the best available information."

Several organizations suggest the CPSO revise its guidelines to adopt the much more modest approach taken in British Columbia, which directs physicians to employ a rigorous medical approach before offering any unorthodox therapy (www.cpsbc.ca/files /u6/Complementary-and-Alternative -Therapies.pdf). — Lauren Vogel, CMAJ

CMAJ 2011. DOI:10.1503/cmaj.109-4004

\section{More news online}

Educating patients with pictures: The McGill University Health Centre in Montréal, Quebec, has created a new patient education guide (www.cmaj.ca/lookup/doi/10.1503/cmaj.109-3967). — Roger Collier, CMAJ

Soda war heats up: (www.cmaj.ca/lookup/doi/10.1503/cmaj.109-3965). Wendy Glauser, Toronto, Ont.

South Africa failing women as abuse of maternity patients runs rampant, report says: (www.cmaj.ca/lookup/doi/10.1503/cmaj.109-3962). — Lauren Vogel, CMAJ

Canada instrumental in watering down elements of noncommunicable diseases plan: (www.cmaj.ca/lookup/doi/10.1503/cmaj.109-4008). — Paul Christopher Webster, Toronto, Ont.

Brazilian health care faces harsh choices: (www.cmaj.ca/lookup/doi /10.1503/cmaj.109-3996). — Tiago Villanueva MD, Lisbon, Portugal

UN summit urges more accountability within food and beverage industry: Secretary General calls for more ethical behaviour (www.cmaj.ca /lookup/doi/10.1503/cmaj.109-4010). - Paul Webster, New York City, NY

The missing elements of the noncommunicable diseases action plan: Summit delegates sketch deficiencies in action plan (www.cmaj.ca/lookup /doi/10.1503/cmaj.109-4011). — Paul Christopher Webster, New York City, NY

Patient navigators becoming the norm in Canada: (www.cmaj.ca /lookup/doi/10.1503/cmaj.109-3974). — Erin Walkinshaw, Ottawa, Ont.

Centralized, nationwide electronic health records schemes under assault: (www.cmaj.ca/lookup/doi/10.1503/cmaj.109-4001). _ Paul Christopher Webster, Toronto, Ont.

CMAJ 2011. DOI:10.1503/cmaj.109-4007 